\title{
"The use and trend of emotional language in the banks' annual reports: the state of the global financial crisis"
}

\begin{tabular}{|c|c|}
\hline AUTHORS & $\begin{array}{l}\text { Elsayed A. H. Elamir (Dttps://orcid.org/0000-0002-9430-072X } \\
\text { R http://www.researcherid.com/rid/K-3340-2018 } \\
\text { Gehan A. Mousa (D https://orcid.org/0000-0003-2336-5101 } \\
\text { R http://www.researcherid.com/rid/K-3407-2018 }\end{array}$ \\
\hline ARTICLE INFO & $\begin{array}{l}\text { Elsayed A. H. Elamir and Gehan A. Mousa (2019). The use and trend of } \\
\text { emotional language in the banks' annual reports: the state of the global financial } \\
\text { crisis. Banks and Bank Systems, 14(2), 9-23. doi:10.21511/bbs.14(2).2019.02 }\end{array}$ \\
\hline DOI & http://dx.doi.org/10.21511/bbs.14(2).2019.02 \\
\hline RELEASED ON & Monday, 22 April 2019 \\
\hline RECEIVED ON & Wednesday, 16 January 2019 \\
\hline ACCEPTED ON & Tuesday, 02 April 2019 \\
\hline LICENSE & $\begin{array}{l}(c)) E Y \\
\text { This work is licensed under a Creative Commons Attribution } 4.0 \text { International } \\
\text { License }\end{array}$ \\
\hline JOURNAL & "Banks and Bank Systems" \\
\hline ISSN PRINT & $1816-7403$ \\
\hline ISSN ONLINE & $1991-7074$ \\
\hline PUBLISHER & LLC "Consulting Publishing Company "Business Perspectives" \\
\hline FOUNDER & LLC "Consulting Publishing Company "Business Perspectives" \\
\hline
\end{tabular}

NUMBER OF REFERENCES

57

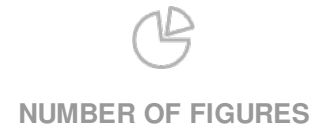

3
NUMBER OF TABLES

9

(C) The author(s) 2022. This publication is an open access article. 


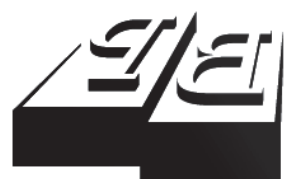

BUSINESS PERSPECTIVES

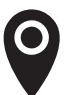

LLC "CPC "Business Perspectives" Hryhorii Skovoroda lane, 10, Sumy, 40022, Ukraine

www.businessperspectives.org

Received on: $16^{\text {th }}$ of January, 2019 Accepted on: $2^{\text {nd }}$ of April, 2019

(C) Elsayed A. H. Elamir, Gehan A. Mousa, 2019

Elsayed A. H. Elamir, Ph.D. Associate Professor, College of Business Administration, University of Bahrain, Kingdom of Bahrain.

Gehan A. Mousa, Ph.D., Associate Professor, College of Business Administration, University of Bahrain, Kingdom of Bahrain.

\section{(c) (1)}

This is an Open Access article, distributed under the terms of the Creative Commons Attribution 4.0 International license, which permits unrestricted re-use, distribution, and reproduction in any medium provided the original work is properly cited.

\section{THE USE AND TREND OF EMOTIONAL LANGUAGE IN THE BANKS' ANNUAL REPORTS: THE STATE OF THE GLOBAL FINANCIAL CRISIS}

\begin{abstract}
This study is of an exploratory nature as it seeks to explore the extent to which the language of emotions in the banks' annual reports is affected by the global financial crisis (GFC). The language of emotions was analyzed using eight categories (trust, anticipation, sadness, anger, fear, disgust, surprise and joy) in annual reports of 12 listed banks from six countries in the Middle East area (namely, Jordan, Kingdom of Bahrain, United Arab Emirates, Sultanate of Oman, Kuwait, Kingdom of Saudi Arabia) from 2002 to 2017. The final data set consists of 192 bank-year observations. The study time was divided into three periods (pre, during and post GFC). In addition, the study enriches accounting literature by being the first study to test Pollyanna hypothesis using emotion analysis. The results of the study show that the percentage of emotional words in banks' annual reports (2002-2017) represents almost $22 \%$ on average. The trust, anticipation and fear categories were the most affected than other emotional categories during GFC. While the trust category decreased, both the fear and anticipation categories increased. Other findings of the study show that regardless of GFC, emotional words of trust and anticipation categories in banks' annual reports have dominated the emotional words of the disgust and surprise categories. Therefore, Pollyanna hypothesis is supported. In contrast to the emotional words of the joy category in banks' annual reports which has not dominated the sadness category. In this case, Pollyanna hypothesis is rejected.
\end{abstract}

\section{Keywords}

JEL Classification banks' annual reports, global financial crisis, emotion analysis, Pollyanna hypothesis

\section{INTRODUCTION}

The global financial crisis (GFC) at the beginning of 2008 has had negative and serious impacts on many financial institutions in all countries of the world, especially the banks that were among the victims of this crisis. Many banks, especially in the United States (US), have been affected by GFC. Some banks have tried to survive, while others have collapsed (Alnajjar et al., 2010; Wall Street Journal, 2007; Olaniyi \& Olabisi, 2011). The financial system in the banks faced severe financial difficulties during GFC. The crisis was preceded by a direct growth in the debt ratio with a sharp rise in the prices of assets and real estate and a severe shortage of liquidity. The top management in banks did not notice that risk until some banks collapsed (Norris, 2007; Wall Street Journal, 2007). Because of the great effects of GFC on various aspects of business and financial markets, many researchers and analysts have examined these effects in different ways that led to the richness of accounting literature. For example, Nazir et al. (2012) analyzed the impact of GFC on the banks' financial performance in Pakistan, Chan-Lau (2010) investigated the effect of GFC on the Chilean bank- 
ing system, while Olaniyi and Olabisi (2011) reported the negative effects of GFC on the financial performance of the banking sector in Nigeria, namely deposits, advances, and investments. The report of the United Nations (UN) in 2011 titled "World Economic Situation and Prospects 2011" pointed out that "the effect of GFC is expected to continue into 2011 and 2012 as weaknesses in major developed economies continue to provide a drag on the global recovery and pose risks for world economic stability in the coming years" (UN, 2011, p. iii). The importance of the topic of GFC gives the motivation for the current study that seeks to explore the impact of GFC on the use of the language of emotions in banks' annual reports from six countries in the Middle East area over 16 years (from 2002 to 2017). In addition, it tests the validity of Pollyanna hypothesis, which argues that regardless of the performance, or circumstances of the companies, managers will continue to use positive expressions rather than negative ones (Hildebrandt \& Snyder, 1981).

The beginning of the 80 's has witnessed a great deal of interest by many researchers to study corporate annual reports, the language, content, and style. Corporate annual reports occupy a special and unique position for a large segment of users such as shareholders, investors, analysts, lenders, regulators and others (Arfin, 1993; Thomas, 1997). Consequently, accounting literature (Loughran \& McDonald, 2011; Chen, 2014; Huang et al., 2014; Loughran \& McDonald, 2014) offers several studies on the analysis of language and the content of firms' annual reports. The results of these studies indicate that firms' annual reports contain a stock of information about corporate financial performance as well as other information indicating financial risks or fraud. For example, Jaeschke et al. (2018, p. 174) pointed out that "the language used in the Securities and Exchange Commission (SEC) filings has been shown to provide information about a firm's market and litigation risks". In this regard, Tama-Sweet (2014, p. 276) stated that "the tone of earnings announcements provides information to market participants and that this information is impounded into stock price". While, Smith and Taffler (2000) argued that the content of the chairperson's statement is associated with a firm's financial performance. Prior studies reported a direct link between managers' language or tone in financial disclosures and a firm's performance such as $\mathrm{Li}(2008)$ who found that firms with low profits and high risks used complex language in their disclosures to hide their problems. Similar results were reported by Subramanian et al. (1993) who provided evidence on companies' financial reports with good financial performance are more readable and clearer than financial reports of companies with poor performance. Hope et al. (2016) also reported these results. In this line, Kohut and Segars (1992) found that firms with good financial performance use different communication strategies in their annual reports with a different number of words and sentences, which may help to future predict their performance. However, the results of Hildebrandt and Snyder (1981) supported "Pollyanna Hypothesis" that suggests that the language of the Chairman of the Board to shareholders in the annual report will often be positive regardless of the firm's financial performance (Hildebrandt \& Snyder, 1981, p. 5).

The importance of the current study steams from a number of aspects as follows. First, several studies have addressed the content and language of financial disclosures and documented a direct link between such disclosures and different critical matters such as risks, losses, stock prices, illegal acts, fraud, financial performance and financial crisis (Li, 2008; Davis et al., 2012; Tama-Sweet, 2014; Hope et al., 2016). The current study provides a valuable contribution to corporate disclosure literature by using a unique analysis, an emotion analysis, which has not been used in previous studies in the Middle East area. The current study is different from other studies such as Lee et al. (2014) who relied on the sentiment analysis to investigate the association between the textual analyses of financial reports for a sample of US firms and the prediction of stock prices. Similar to Lee et al. (2018) who used the text and data mining to examine the association between sales performance and the text patterns of the US firms' annual reports. "Sentiment analysis is a technique for determining whether a sentence's tone is positive, negative or neutral" (Lee et al., 2018, p. 12). However, in the current study, the emotion analysis as a new and different technique is conducted because it is broader than the sentiment analysis. While emotional analysis includes several emotional words such as confidence, expectation, surprise, fear, and others, the 
sentiment analysis depends on two basic types (positive and negative). Second, this study explores the effect of GFC on using the emotional language in 12 banks' annual reports, from 2002 to 2017. This period has been divided into three different times, mainly the pre-crisis (2002-2007), during crisis (20082012) and the post-crisis (2013-2017). Consequently, it offers unique implications for many participants in different capital markets such as investors, regulators and other stakeholders. Finally, the study is characterized by some practical implications. For example, emotional analysis of annual reports can be used by analysts in financial markets, auditors and investors as an extra tool rather than an alternative to their approaches that can add value and help them to make decisions.

This paper is organized as follows. Section 1 provides literature on using language style or tone in corporate disclosure. Section 2 presents a theoretical framework of the study and hypotheses development. Section 3 provides the research method and the sample of the current study. Section 4 shows the empirical analysis and results. The final section summarizes the conclusions.

\section{LITERATURE REVIEW}

The idea of studying the language style or tone in financial reports dates to relatively old studies. For example, Hildebrandt and Snyder (1981) studied the frequency of use of positive and negative words in financial reports as an attempt to answer the question of whether the language used by companies in their financial reports varies according to their performance. At the same time, do companies use more positive words than negative ones in their reports even if their financial performance is bad? A similar study was conducted by Thomas (1997). The results of both studies showed that companies use positive words more than negative words regardless of their financial performance. Moreover, a number of prior studies indicated that using the language analysis of financial reports provides valuable information to various decision makers on several matters such as the future of the company, financial performance, risks, corporate corruption and others (Henry, 2008; Rogers et al., 2011; Jaeschke et al., 2018). Despite the association between management language in annual reports or disclosure tone and firm performance, which has started to receive major interest in accounting literature, the findings are mixed.

A stream of studies (Davis et al., 2012) documented a relationship between managers' use of optimistic language to express the firm's future performance, in their reports to stockholders and investors. For example, the results of Huang et al. (2014) indicated that managers use a biased language, which is the optimistic language when the company's financial performance is bad. Kothari et al. (2009) reported that the firm's stock return volatility is significantly associated with a negative tone in corporate disclosures. Tetlock et al. (2008) found a relationship between a firm's future earnings and the tone of corporate disclosure, which suggests that managers use the tone, which reflects future stock returns. Chen (2014) used the text analysis of firms' annual reports focusing on narrative sections in these reports to detect fraud. The author filtered fraudulent language in texts of these reports and differentiated between fraudulent and non-fraudulent annual reports. Chen (2014) concluded that the language in firm's annual reports could indicate the possibility of fraud. This is similar to Goel et al. (2010) who investigated fraud in corporate financial disclosure and found that the writing style of fraudulent firms is different from non-fraudulent firms because fraudulent firms use long paragraphs with long sentences so that their reports are less readable. In Egypt, Aly et al. (2018) found that financial performance of Egyptian firms is one of the main determinants of tone disclosure where Egyptian firms disclose more information when they have good news related to their financial performance. In US, the results of Jaeschke et al. (2018) reported that violating companies for the Foreign Corrupt Practices Act (FCPA) use less conservative and litigious language with more complex words in their financial disclosures compared to non-violators. Another stream of studies (Kothari et al., 2009; Loughran \& McDonald, 2011; Jegadeesh \& Wu, 2013; Mayew et al., 2014) examined the association between management's language in SEC filings and stock return volatility, market risks and analyst forecast. These studies documented that firms' language is 
more negative when they face risks, bankruptcy, loss or financial problems.

On the other hand, Rogers et al. (2011) presented conflicting results. The authors pointed out that companies facing legal problems use a more optimistic language in their financial reports. In the same line, Nelson and Pritchard (2016) showed that firms with litigation risks provide more readable financial disclosures than other firms. Schleicher and Walker (2010) showed that firms with losses use more positive tone in their disclosures compared to firms with earnings which provide a more negative tone. Using sentiment analysis, Lee et al. (2018) showed that corporate sales performance is not associated with the style of language in the annual report, in other words, a positive or negative tone.

\section{THEORETICAL}

\section{FRAMEWORK OF THE STUDY AND HYPOTHESES DEVELOPMENT}

\subsection{Theoretical framework of the study}

Several theoretical perspectives provide different explanations for managers' motivations for corporate disclosure such as stakeholder theory, legitimacy theory, agency theory and signaling theory. However, agency theory is one of the most widely used theories to explain corporate disclosure and managers' behavior and their choice of a certain information to disclose or to avoid the disclosure of other information. Agency theory offers a number of advantages for corporate disclosure such as reducing information asymmetry (Watson et al., 2002), conflicts of interest between managers and owners (Jensen \& Meckling, 1976), and the cost of capital (Easley \& O'Hara, 2004; Rajgopal \& Venkatachalam, 2011). In line with agency theory, it can be argued that corporate disclosure provides an opportunity for the company to create a certain image of the company in the minds of investors and convince them that the company is working well to maximize their benefits (Abraham \& Cox, 2007). The current study tests the extent to which the emotional language in the annual reports of a sample of banks is affected by GFC. It is argued that managers use the emotional language in their annual reports to deliver a specific message to the company's stakeholders. This message may be related to financial performance and other matters. Accounting literature provides evidence through some studies on the use of language styles in financial reporting in a biased manner related to the financial performance of the company (Davis et al., 2012; Huang et al., 2014).

\subsection{Hypotheses development}

The general Pollyanna hypothesis in business suggests "Regardless of the financially good or bad years of a corporation, the communication in the annual letters to the stockholders will be predominantly positive" (Hildebrandt \& Snyder, 1981, p. 5). The current study tested the validity of Pollyanna hypothesis in terms of using the emotional language in banks' annual reports. It used eight basic emotional categories (joy against sadness, anger against fear, trust against disgust, and surprise against anticipation) that suggested by Plutchik (1980, p. 1) (more details on these emotional categories are explained in the research method section).

Based on the previous discussion, the following hypotheses are suggested:

H1: The emotional words of the trust category dominate the emotional words of the disgust category in banks' annual reports regardless of GFC.

H2: The emotional words of the joy category dominate the emotional words of the sadness category in banks' annual reports regardless of GFC.

H3: The emotional words of the anticipation category dominate the emotional words of the surprise category in banks' annual reports regardless of GFC.

H4: The emotional words of the fear category dominate the emotional words of the anger category in banks' annual reports regardless of GFC. 


\section{RESEARCH METHOD}

\subsection{Emotion analysis (the lexicon-based approach)}

Since the main objective of the current study is to explore the effect of GFC on the use and trend of emotional words in 192 banks' annual reports from six countries over 16 years (2002-2017), emotion analysis was used. This analysis is seen as the science of studying and extracting information that expresses a person's feeling through speaking, text, film, photo and other aspects. Recognition of emotional language from text is a new field of study that is connected to sentiment analysis (Ortony et al., 1988). The sentiment analysis is extracting and recognizing feeling such as positive, negative and neutral (Saif et al., 2012). While the emotion analysis is seeking to extract and recognize feeling in a wider range with several categories such as trust, disgust, fear, joy, sadness and others (Ortony et al., 1988; Batson, 1992; Conrad \& Biber, 2000; Scheibman, 2002; Pang \& Lee, 2004). Recently, emotion analysis is used in many research fields including business, engineering and information technology (Aman \& Szpakowicz, 2007; Bellegarda, 2010; Li, 2018) as well as in different cultures. For example, Ekman and Freisen (1971) divided the basic emotions into six categories: anger, disgust, fear, happiness, sadness and surprise (for more details, see Ekman, 1992; Ekman \& Cordaro, 2011). In 1980, Plutchik introduced the concept of "wheel of emotion" that depends on how several emotions can be mixed into one another to make new emotion". Plutchik (1980) proposed eight basic emotions: "each composed of two basic ones: joy against sadness; anger against fear; trust against disgust; and surprise against anticipation" (Plutchik, 1980, p. 1). These eight basic emotions suggested by Plutchik (1980) were used in the current study.

In general, there are two approaches for the problem of extracting emotions automatically. First, the lexicon-based approach which depends on ready words or phrases bag from known lexicon and calculating emotional words or phrases in a document using a software (Aman \& Szpakowicz, 2007). Second, the text classification approach which creates data from the classifying of texts or sentences (Pang et al., 2002). In this study, the lexicon-based approach is followed in which the dictionaries of words are annotated with the word's emotional orientation where emotions can be expressed in textual forms using words. It has a rich library with emotional words that are the most common in social sciences.

R-software was used that offers "NRC" lexicon via the "tidy" and "syuzhet" packages, in the current study, to identify the emotional words expressed in the text $t^{1}$. Such packages include several words for emotional expressions that were collected in eight categories (joy against sadness; anger against fear; trust against disgust; and surprise against anticipation) and two sentiments (positive against negative). The eight categories are the same as those suggested by Plutchik (1980).

\subsection{The sample}

The aim of this study is to explore the impact of GFC on the use of emotional language in the banks' annual reports through three periods (the pre-GFC from 2002 to 2007, during GFC from 2008 to 2012, and the post-GFC from 2013 to 2017). Selecting the sample in the current study is based on the availability of language data, in other words, listed banks' annual reports for the 16 year-period (from 2002 to 2017) from six countries (namely, Jordan, Kingdom of Bahrain, United Arab Emirates, Sultanate of Oman, Kuwait, Kingdom of Saudi Arabia). Listed banks in these countries, which have missing annual reports for the period 2002 to 2007, were excluded. Consequently, the final data set consists of 192 bank-year observations. Table 1 shows details of the sampled banks and their distribution within six countries (namely, Jordan, Kingdom of Bahrain, United Arab Emirates, Sultanate of Oman, Kuwait, Kingdom of Saudi Arabia). A list of banks used in the current study is shown in Appendix A.

1 For more details, see Mohammad (2018) and Saif et al. (2012). 
Table 1. Distribution of sample banks selected for the current study

\begin{tabular}{l|c|c|c}
\hline Country name & $\begin{array}{c}\text { Number } \\
\text { of listed } \\
\text { banks }\end{array}$ & $\begin{array}{c}\text { Number } \\
\text { of } \\
\text { selected } \\
\text { banks }\end{array}$ & $\begin{array}{c}\text { Percentage } \\
\text { of selected } \\
\text { banks }\end{array}$ \\
\hline Kingdom of Bahrain & 7 & 2 & 28.5 \\
\hline United Arab Emirates & 10 & 2 & 20 \\
\hline Sultanate of Oman & 7 & 1 & 14 \\
\hline Jordan (three banks) & 12 & 3 & 25 \\
\hline Kuwait & 8 & 2 & 25 \\
\hline Kingdom of Saudi & 11 & 2 & 18 \\
Arabia & 12 & & \\
\hline $\begin{array}{l}\text { Total number of } \\
\text { selected banks }\end{array}$ & & & \\
\hline
\end{tabular}

\subsection{Empirical analysis and results}

The use of language by managers in the corporate annual reports has occupied the top of the agenda of interest by researchers because of the special importance of these reports as a main source of useful information for the majority of business clients such as investors, lenders, regulators, financial institutions and others. Several accounting studies in the area of corporate disclosure investigate how managers use different language styles in their annual reports. For example, some studies show that managers tend to use positive or optimistic styles in their financial reports to attract more investors, especially if the company achieves good financial performance (Lee et al., 2014; Jaeschke et al., 2018).

\subsection{The descriptive analysis}

The current study seeks to explore the extent to which the language of emotions in the banks' annual reports is affected by GFC. Consequently, the study period from 2002 to 2017 (16 years totally), was divided into three periods (pre, during and post) of GFC as mentioned early in the current study. Moreover, eight emotional categories were used (trust, anticipation, surprise, fear, anger, sadness, joy and disgust). To recognize the trend of all emotional words in banks' annual reports (from 2002 to 2017), Figure 1 was prepared.

In Figure 1, the percentage of emotional words in the annual reports of some banks (AUB, DIB, MASQ, HBMO, THBK, GBK and SAAB) in the pre-GFC was $20 \%$ to $22 \%$, while it was $23 \%$ to $25 \%$ during GFC, and in the post-GFC it amounted $22 \%$ to $24 \%$. The pattern of emotional words in BBK is characterized by volatility, as the bank's usual pattern is $22.5 \%$ before 2007 and after 2013 . While the percentage of emotional words in BBK increased from $20 \%$ in 2009 to $30 \%$ in 2010 . For EXFB, the average percentage of emotional words in the annual reports of EXFB is $22.5 \%$ for the three periods (pre, during and post GFC) except for the year 2013 where the percentage of emotional words went down to approximately $1 \%$. The percentage of emotional words for BURG is almost $22.5 \%$ for two periods (pre and post-GFC).

Table 2. The percentage of overall emotional words in banks' annual reports (from 2002 to 2017)

\begin{tabular}{|c|c|c|c|c|c|c|c|c|c|c|c|c|}
\hline Year & AUB & BBK & DIB & MASQ & HBMO & EXFB & THBK & JOKB & BURG & GBK & SAAB & NCB \\
\hline 2002 & 20.5 & 21 & 20.5 & 19.2 & 20.3 & 23.8 & - & 21.8 & 23.1 & - & - & - \\
\hline 2003 & 21.4 & 21.4 & 20.5 & 20.8 & 20.2 & 23.8 & 23.5 & 23.1 & 24.3 & 18.5 & - & - \\
\hline 2004 & 21.8 & 21 & 21.5 & 20.1 & 20.4 & 23.4 & 24 & 22.7 & 24 & 21.4 & - & - \\
\hline 2005 & 22.6 & 19.6 & 21.5 & 20.1 & 19.5 & 23.4 & 22.8 & 23.4 & 23.7 & 19.3 & - & - \\
\hline 2006 & 22.9 & 19.6 & 20.9 & 19.9 & 18.7 & 23.3 & 24.2 & 24.5 & 26.7 & 22.1 & 10.1 & 6.1 \\
\hline 2007 & 22.9 & 19.9 & 19.9 & 19.4 & 18.7 & 23.2 & 23.6 & 24.5 & 10.3 & 22.3 & 23 & 6.1 \\
\hline 2008 & 22.4 & 28.9 & 20.7 & 19 & 19.5 & 24 & 23.6 & 24.4 & 10.6 & 23.4 & 6.1 & 35.8 \\
\hline 2009 & 22.9 & 19.1 & 20.4 & 19.7 & 19.8 & 24.4 & 22.4 & 24.1 & 24.2 & 24.4 & 14.3 & 30.9 \\
\hline 2010 & 23.4 & 22 & 20.4 & 20.1 & 20.2 & 24.4 & 22.4 & 24.7 & 10 & 24.3 & 14.4 & 17.6 \\
\hline 2011 & 22.9 & 21.6 & 19.9 & 19.6 & 20 & 0.10 & 22.4 & 24.5 & 24.2 & 24.5 & 11.9 & 13.1 \\
\hline 2012 & 22.7 & 20.3 & 20.2 & 19.5 & 19.6 & 24.8 & 23.2 & 24.6 & 22.7 & 24.6 & 11.2 & 16.2 \\
\hline 2013 & 22.4 & 21 & 20.2 & 19.2 & 20 & 23.3 & 23 & 25 & 22.6 & 25.2 & 0.01 & 16.8 \\
\hline 2014 & 23.1 & 21 & 20.1 & 19.4 & 19.4 & 23 & 22.8 & 23 & 22.2 & 24.5 & 33.2 & 0.01 \\
\hline 2015 & 22.5 & 20.8 & 19.7 & 19.5 & 20.3 & 23 & 22.5 & 23.6 & 22.3 & 24.8 & 16 & 43.8 \\
\hline 2016 & 22.4 & 22.7 & 20.1 & 19.4 & 19.4 & 23 & 21.6 & 22.9 & 21.8 & 24.6 & 16.4 & 9.5 \\
\hline 2017 & 22.3 & 23.3 & 28.1 & 18 & 19.8 & 24.1 & 22.1 & 22.8 & 21.6 & 24.6 & 12.5 & 19.6 \\
\hline
\end{tabular}



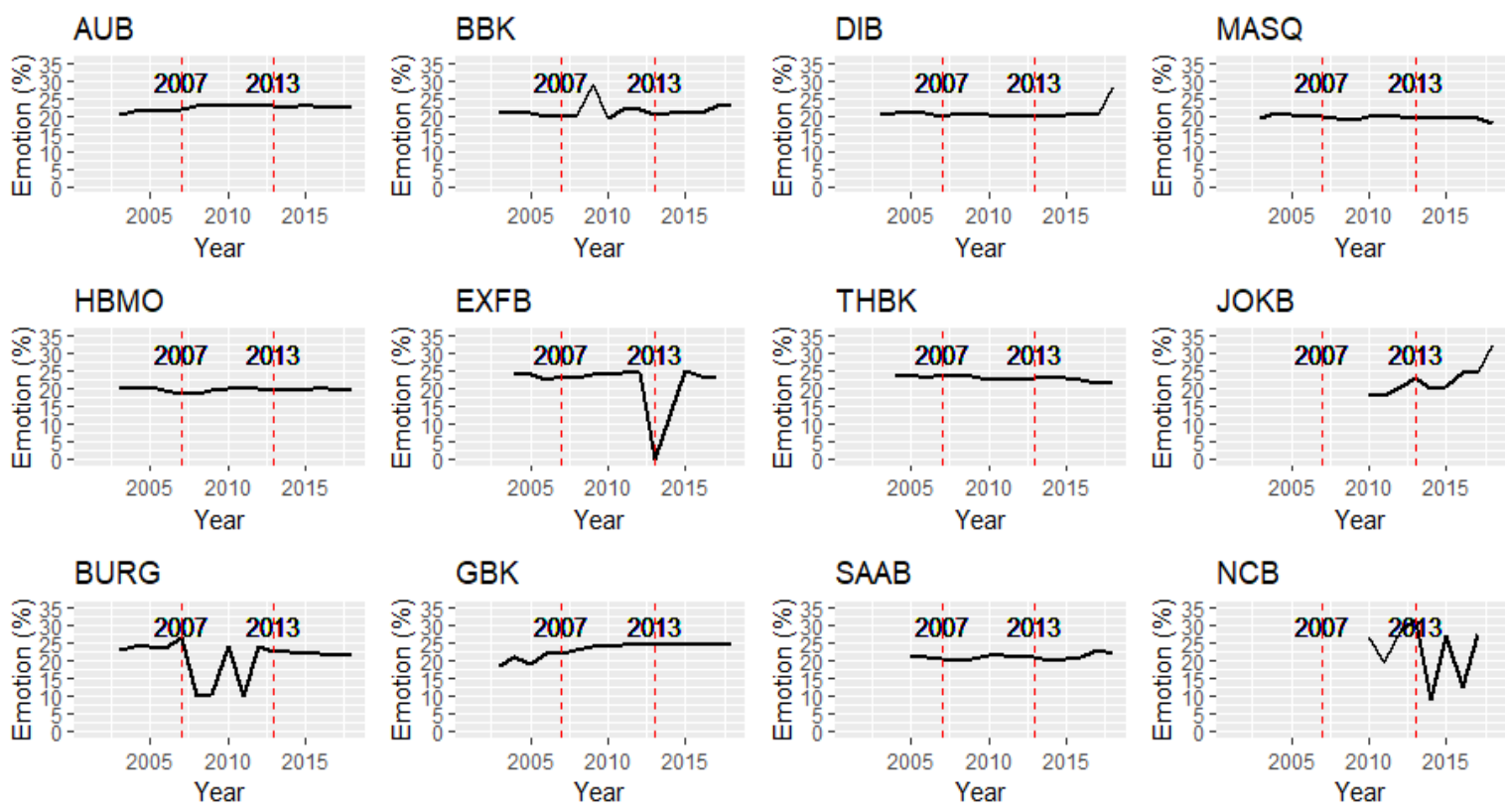

Figure 1. The trend of all emotional words in banks' annual reports (from 2002 to 2017)

In contrast, the percentage of emotional words is approximately $10 \%$ in 2008 and approximately $25 \%$ in 2010 . The percentage of emotional words in JOKB started in 2010 by about $17.5 \%$ to reach $22 \%$ in 2013. After this year, it started to decline to $20 \%$ in 2014 and 2015 , and then the percentage reached $30 \%$ in 2017 . Finally, the percentage of emotional words in NCCB was $25 \%$ in 2010 but then declined to $20 \%$ in 2011 . It was about $30 \%$ in years 2012 and 2013. In contrast, the percentage of emotional words of NCCB reached $10 \%$ in 2014 as the lowest level, while it reached $30 \%$ in both 2015 and 2017 as the highest level.

Table 2 shows the percentage of overall emotional words in each bank from 2002 to 2017. It can be seen that the highest percentage is 43.8 and the lowest percentage is 0.01 and the mid-mean is $(43.8+0.01) / 2 \approx 22$.

It should be noted that all the graphs in Figure 1 indicate that the percentage of emotional words in banks' annual reports (from 2002-2017) represents almost $25 \%$ on average. Such a percentage is relatively large, which needs further analysis to determine the percentage and the use of each emotional category (eight categories were used in the current study), in addition to knowing whether the use of each emotional category was affected by the three different periods of GFC.
Consequently, Table 3 shows the descriptive analysis of the eight categories of emotional words of sampled banks in the study. In Table 3, the trust category is accounted for $36.5 \%$ to $46 \%$ from the total number of emotional words in the sample banks' annual reports with the highest average in THBK and the lowest average in HBMO. The anticipation category is scored for $21 \%$ to $23.9 \%$ from all emotional words in banks' annual reports with the highest average in AUB and the lowest average in NCB. Moreover, the fear category is accounted for $8.31 \%$ to $15.3 \%$ with the highest average in MASQ and the lowest average in JOKB. The joy category accounts for $8.53 \%$ to $11.7 \%$ with the highest average in BID and the lowest average in MASQ. While the anger category accounts for $4.62 \%$ to $7.75 \%$ from all emotional words in banks' annual reports used in the current study with the highest average in DIB and the lowest average in JOKB. The sadness category is earned for $4.88 \%$ to $8.59 \%$ with the highest average in JOKB and the lowest average in BURG. In addition, the surprise category is accounted for $1.64 \%$ to $2.91 \%$ with the highest average in GBK and the lowest average in DIB. Finally, the disgust category is accounted for $0.81 \%$ to $2.43 \%$ with the highest average in GBK and the lowest average in DIB

List of 12 banks used in the current study and their codes in six stock exchanges are present- 
Table 3. The descriptive analysis of the eight categories of emotional words of sampled banks in the current study

\begin{tabular}{|c|c|c|c|c|c|c|c|c|c|c|c|c|c|}
\hline \multirow{2}{*}{$\begin{array}{l}\text { Eight categories } \\
\text { of emotional } \\
\text { words }\end{array}$} & \multicolumn{13}{|c|}{ Banks } \\
\hline & & AUB & BBK & DIB & MASQ & HBMO & EXFB & THBK & JOKB & BURG & GBK & SAAB & NCB \\
\hline \multirow{2}{*}{ Trust } & Mean & 40.40 & 40.9 & 37.90 & 37.90 & 36.50 & 42.50 & 46.00 & 43.80 & 43.30 & 42.90 & 39.30 & 42.10 \\
\hline & SD & 1.55 & 3.65 & 5.73 & 2.26 & 1.09 & 6.41 & 0.92 & 1.42 & 3.42 & 4.07 & 1.15 & 2.17 \\
\hline \multirow{2}{*}{ Anticipation } & Mean & 23.90 & 23.70 & 22.20 & 22.2 & 23.40 & 21.90 & 22.30 & 23.40 & 22.60 & 21.10 & 22.10 & 21.00 \\
\hline & SD & 2.06 & 2.13 & 1.64 & 1.52 & 1.89 & 2.96 & 1.35 & 2.06 & 1.21 & 1.28 & 1.44 & 2.24 \\
\hline \multirow{2}{*}{ Fear } & Mean & 12.10 & 11.70 & 11.70 & 15.30 & 10.30 & 10.80 & 8.40 & 8.31 & 10.80 & 12.30 & 12.60 & 9.73 \\
\hline & SD & 1.96 & 3.67 & 2.81 & 3.66 & 2.06 & 5.81 & 0.98 & 0.47 & 2.27 & 3.31 & 1.68 & 1.56 \\
\hline \multirow{2}{*}{ Joy } & Mean & 10.20 & 9.27 & 11.70 & 8.53 & 11.6 & 8.69 & 9.13 & 8.62 & 10.2 & 8.67 & 11.00 & 11.5 \\
\hline & SD & 1.25 & 2.09 & 2.27 & 2.23 & 1.26 & 3.01 & 1.25 & 1.78 & 1.94 & 1.11 & 1.95 & 0.93 \\
\hline \multirow{2}{*}{ Sadness } & Mean & 5.07 & 5.00 & 6.50 & 6.47 & 7.75 & 8.15 & 7.00 & 8.69 & 4.88 & 5.33 & 5.00 & 5.27 \\
\hline & SD & 0.99 & 0.92 & 1.93 & 1.06 & 1.39 & 0.89 & 0.53 & 0.60 & 1.31 & 1.76 & 0.00 & 1.95 \\
\hline \multirow{2}{*}{ Anger } & Mean & 4.86 & 5.27 & 7.75 & 6.87 & 5.75 & 5.54 & 4.80 & 4.62 & 4.94 & 5.47 & 6.00 & 6.45 \\
\hline & SD & 1.10 & 1.28 & 2.30 & 1.06 & 0.57 & 1.13 & 0.94 & 1.36 & 1.18 & 0.51 & 0.95 & 1.92 \\
\hline \multirow{2}{*}{ Surprise } & Mean & 2.29 & 2.80 & 1.64 & 2.00 & 3.00 & 1.92 & 1.80 & 2.00 & 2.44 & 1.80 & 2.75 & 2.91 \\
\hline & SD & 0.61 & 1.08 & 0.50 & 0.37 & 0.00 & 0.29 & 0.41 & 0.00 & 0.42 & 0.41 & 0.45 & 0.83 \\
\hline \multirow{2}{*}{ Disgust } & Mean & 1.64 & 1.33 & 0.81 & 0.86 & 2.19 & 1.00 & 0.93 & 1.00 & 0.94 & 2.43 & 1.00 & 1.27 \\
\hline & SD & 0.49 & 0.72 & 0.40 & 0.35 & 0.40 & 0.00 & 0.25 & 0.00 & 0.25 & 1.02 & 0.00 & 0.46 \\
\hline
\end{tabular}

Note: Eight categories of emotional words (Trust, Anticipation, Fear, Joy, Sadness, Anger, Surprise and Disgust). The standard deviation (SD).

ed in Appendix A. The final data set consists of 192 bank-year observations. Results are shown in Table 3 related to the period from 2002 to 2017.

\subsection{The distribution and trend of emotional words in banks' annual reports}

Figure 2 shows the distribution of eight emotional categories in banks' annual reports (from 2002-2017). In Figure 2, Boxplot reflects the distributional characteristics of emotional words in terms of median, skewness and outliers as well as the level of the emotional words. It can be noted that the emotional words of the trust category are the highest and most frequently used in the annual reports of the sampled banks. In contrast, the emotional words of the disgust category are the least commonly used in these annual reports. For example, in AUB, the trust category is ranked first with median percentage of $42 \%$. The anticipation category is the second with median percentage of $25 \%$ and the third category is fear with median percentage of $13 \%$. In addition, the fourth category is joy with median percentage of $11 \%$, the fifth category is sadness with median percentage of $7 \%$, the sixth category is anger with median percentage of $5 \%$, the seventh category is surprise with median percentage of $3 \%$ and the eighth category is disgust with median percentage of $1 \%$.

This result is logical and predictable as it is known that managers are trying to gain investor confidence by using the language that generates confidence and trust in their annual reports. Therefore, the emotional words of the trust category are used extensively and consistently throughout all banks (from 2002-2017). At the same time, managers try to avoid any language style that can alienate investors such as the emotional words of the disgust, anger, sadness, and surprise categories. Such categories are the least commonly used in banks' annual reports. The anticipation category is ranked second in terms of use by managers in banks' annual reports. Moreover, the emotional words of the fear and joy categories in all banks' annual reports overall 16 years appear very close to each other and have the same behavior. These results are consistent with a number of studies, which argue that managers use language or tone in annual reports to impact different users of these reports and to send a specific message to them (see, for 

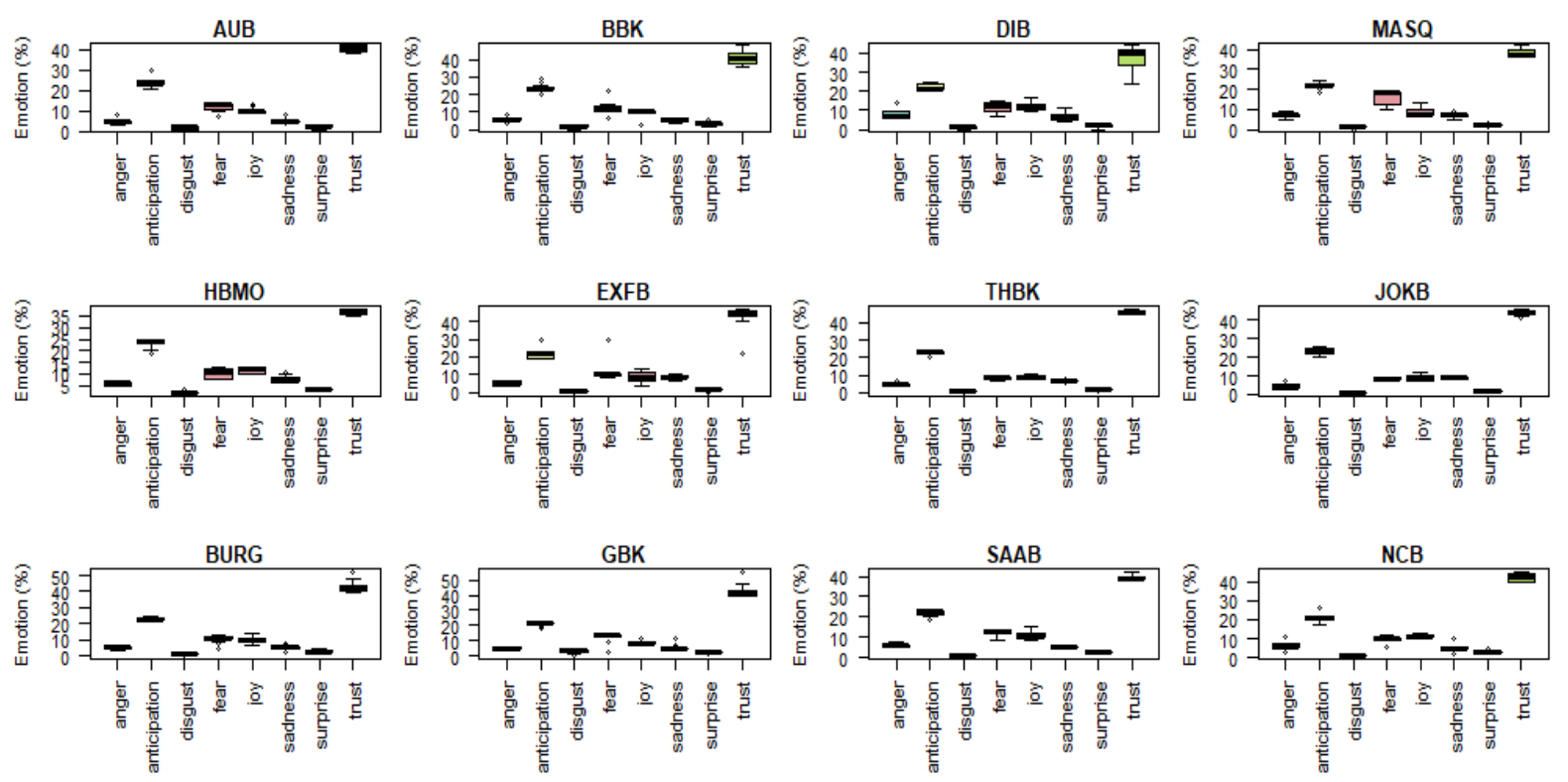

Figure 2. The boxplot for each emotional category in banks' annual reports (from 2002 to 2017)

example, Li, 2008; Davis et al., 2012; Tama-Sweet, 2014; Hope et al., 2016). To trace the changes in each emotional category and how each category is affected through the three intervals of GFC (pre, during and post), Figure 3 was prepared.

Figure 3 reflects the importance of eight emotional categories in each bank from 2002 to 2017. It can be noted that there are three categories (trust, anticipation and fear) that are more affected than other emotional categories. For example, the trust category is most affected during the GFC period (from 2008-2012). It de- clined in most banks (AUB, BBK, DIB, MASQ, HBMO, JOKB, SAAB, BURG, GBK and NCB) (about $10 / 12=83 \%$ ). In contrast, the fear category rose (about $8 / 12=75 \%$ ) in AUB, BBK, DIB, BURG, SAAB and NCB, MASQ and EXFB (during GFC). This is similar to the anticipation category which increased generally in the same period in AUB, BBK, MASQ, HBMO, EXFB, THBK, JOKB, GBK, SAAB, while the anticipation category declined in NCB $(10 / 12=83 \%)$. To summarize, during the GFC, the trust category decreased, while both the fear and anticipation categories increased.
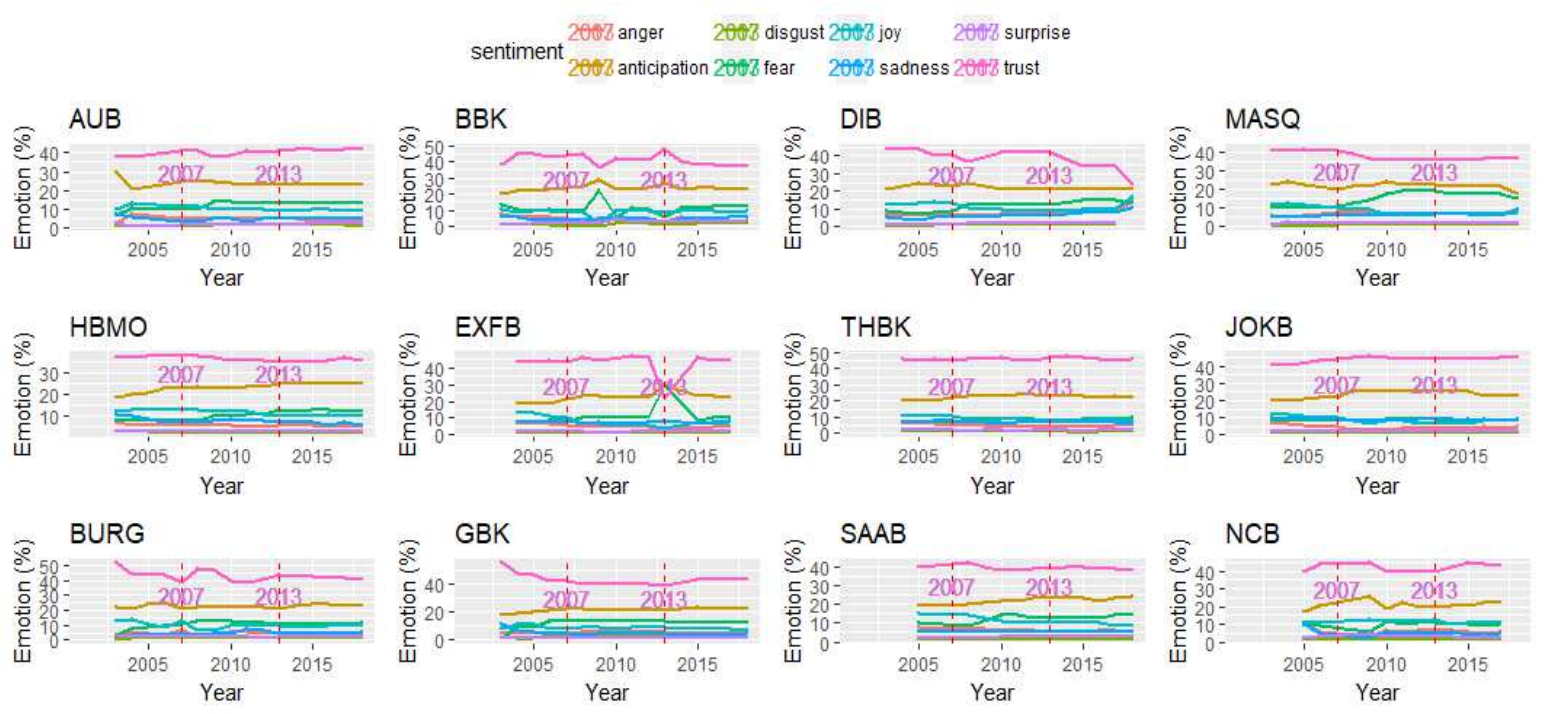

Figure 3. The trend of the eight emotional categories in banks' annual reports (from 2002 to 2017) 


\subsection{The Wilcoxon rank-sum test ${ }^{2}$}

The period of the current study was divided into three periods, namely pre-GFC from 2002 to 2007; during GFC from 2008 to 2012; post-GFC from 2013 to 2017. To identify if there are differences in the use of emotional words in these three periods, the Wilcoxon test was used to test the four hypotheses that were developed earlier in the current study. The Wilcoxon rank-sum test is a nonparametric alternative to the two-sample t-test that is used when the sample size is small and does not require the normal assumption (Sprent \& Smeeton, 2007).

Table 4. Wilcoxon rank-sum test for the emotional words of the trust and disgust categories

(One Tail Two-Sample)

\begin{tabular}{c:ccc}
\hline $\begin{array}{c}\text { H1: The emotional words of the trust category dominate } \\
\text { the emotional words of the disgust category in banks' } \\
\text { annual reports regardless of GFC }\end{array}$ \\
\hline $\begin{array}{c}\text { Codes of } \\
\text { banks }\end{array}$ & $\begin{array}{c}\text { Period 1 } \\
\text { Pre-GFC } \\
\text { (P-value) }\end{array}$ & $\begin{array}{c}\text { Period 2 } \\
\text { During GFC } \\
\text { (P-value) }\end{array}$ & $\begin{array}{c}\text { Period 3 } \\
\text { Post-GFC } \\
\text { (P-value } \approx \text { 0) }\end{array}$ \\
\hline AUB & 0.048 & 0.003 & 0.001 \\
\hdashline BBK & 0.009 & 0.008 & 0.001 \\
\hdashline DIB & 0.002 & 0.021 & 0.019 \\
\hdashline MASQ & 0.002 & 0.003 & 0.001 \\
\hdashline HBMO & 0.005 & 0.003 & 0.001 \\
\hdashline EFXB & 0.005 & 0.004 & 0.035 \\
\hdashline THBK & 0.0001 & 0.0002 & 0.001 \\
\hdashline BURG & 0.004 & 0.003 & 0.001 \\
\hdashline GBK & 0.003 & 0.003 & 0.001 \\
\hline SAAB & 0.049 & 0.004 & 0.003 \\
\hdashline JOKB & 0.007 & 0.0001 & 0.001 \\
\hline NCB & 0.005 & 0.007 & 0.008 \\
\hline
\end{tabular}

Note: The list of banks used in the current study is presented in Appendix A. The final data set consists of 192 bank-year observations.

With respect to $H 1$, Table 4 shows the p-values for the one tail Wilcoxon sum-rank test. The number of significant tests for the trust category has dominated the disgust category at $1 \%$ and $5 \%$ in period 1 (pre-GFC), it is 12 out of 12 (100\%). Similar results are shown in period 2 (during GFC) and in period 3 (post-GFC) it is 12 out of $12(100 \%)$. Based on these results, the Pollyanna hypothesis is confirmed.
Table 5. Wilcoxon rank-sum test for the emotional words of the joy and sadness categories

(One Tail Two-Sample)

H2: The emotional words of the joy category dominate the emotional words of the sadness category in banks' annual reports regardless of GFC

\begin{tabular}{l|c:c:c}
\hline Codes of banks & $\begin{array}{c}\text { Period 1 } \\
\text { Pre-GFC } \\
\text { (P-value) }\end{array}$ & $\begin{array}{c}\text { Period 2 } \\
\text { During GFC } \\
\text { (P-value) }\end{array}$ & $\begin{array}{c}\text { Period 3 } \\
\text { Post-GFC } \\
\text { (P-value) }\end{array}$ \\
\hline AUB & 0.24 & 0.003 & 0.001 \\
\hline BBK & 0.057 & 0.34 & 0.020 \\
\hline DIB & 0.032 & 0.061 & 0.088 \\
\hline MASQ & 0.014 & 0.25 & 0.70 \\
\hline HBMO & 0.003 & 0.004 & 0.012 \\
\hline EFXB & 0.09 & 0.64 & 0.52 \\
\hline THBK & 0.009 & 0.003 & 0.002 \\
\hline BURG & 0.008 & 0.11 & 0.002 \\
\hline GBK & 0.15 & 0.003 & 0.06 \\
\hline SAAB & 0.18 & 0.001 & 0.002 \\
\hline JOKB & 0.21 & 0.94 & 0.75 \\
\hline NCB & 0.20 & 0.014 & 0.057 \\
\hline
\end{tabular}

Note: The list of banks used in the current study is presented in Appendix A. The final data set consists of 192 bank-year observations.

With respect to $H 2$, Table 5 shows the p-values for the one tail Wilcoxon sum-rank test. The number of significant tests for the joy category has dominated the sadness category at $1 \%$ and $5 \%$ in period 1 (pre-GFC), it is 5 out of 12 (42\%). Similar results are shown in period 2 (during GFC) and in period 3 (post-GFC) it is 5 out of 12 (42\%). Consequently, the results do not support $\mathrm{H} 2$, therefore, the Pollyanna hypothesis is not confirmed.

Concerning $H 3$, Table 6 reports the p-values for the one tail Wilcoxon sum-rank test. The number of significant tests for the anticipation category has dominated the surprise category at $1 \%$ and $5 \%$ in period 1 (pre-GFC), it is 12 out of $12(100 \%)$. The number of significant tests in period 2 (during GFC) is 11 out of $12(92 \%)$ and in period 3 (post-GFC), it is 12 out of 12 (100\%). Based on these results, the $\mathrm{H} 3$ is supported, therefore, the Pollyanna hypothesis is confirmed.

For H4, Table 7 reports the p-values for the one tail Wilcoxon sum-rank test. The number of significant tests for the fear category has dominated the anger category at $1 \%$ and $5 \%$ in period 1 (pre-GFC), it is 2 out of 12 (17\%). Therefore, the Pollyanna hypothesis for period 1 is not confirmed. On the other hand, in

2 Note that in the current study, the Wilcoxon rank-sum test was done using the function wilcox.est (x, y, alternative) in R-software. For more details, see, Gibbons and Chakraborti (2003). 
Table 6. Wilcoxon rank-sum test for the emotional words of the anticipation and surprise categories

(One Tail Two-Sample)

\begin{tabular}{l|c|c}
\hline H3: The emotional words of the anticipation category dominate the emotional words of the surprise category in banks' \\
annual reports regardless of GFC
\end{tabular}

Note: The list of banks used in the current study is presented in Appendix A. The final data set consists of 192 bank-year observations.

Table 7. Wilcoxon rank-sum test for the emotional words of the fear and anger categories

(One Tail Two-Sample)

\begin{tabular}{l|c|c|c}
\hline H4: The emotional words of the fear category dominate the emotional words of the anger category in banks' annual \\
reports regardless of GFC
\end{tabular}

Notes: The list of banks used in the current study is presented in Appendix A. The final data set consists of 192 bank-year observations.

period 2 the number of significant tests at $1 \%$ and $5 \%$ is 10 out of $12(83 \%)$ and in period 3 it is 9 out of 12 (75\%). Thus Pollyanna hypothesis is supported for periods 2 and 3 .

The overall Wilcoxon rank-sum test for the whole sample for each period is given in Table 8 , which has shown that the Pollyanna hypothesis is strongly significant for hypotheses $\mathrm{H} 1, \mathrm{H} 2, \mathrm{H} 3$ and $\mathrm{H} 4$ (during period 2 and period 3), while for $\mathrm{H} 4$ (in period), it is very near 0.05 . It can be noted that the results in Table 8 are supported with those shown in previous tables $(4,5,6$ and 7$)$.

Table 8. The overall $p$-value using Wilcoxon ranksum test (one-tail) for a whole sample in each period

\begin{tabular}{c:c:c:c}
\hline$(\boldsymbol{H})$ & Pre-GFC & During GFC & Post-GFC \\
\hline H1 & P-value $\approx 0$ & P-value $\approx 0$ & P-value $\approx 0$ \\
H2 & P-value $\approx 0$ & P-value $\approx 0$ & P-value \\
\hline H3 & P-value $\approx 0$ & P-value $\approx 0$ & P-value $\approx 0$ \\
\hdashline H4 & P-value $\approx 0.049$ & P-value $\approx 0$ & P-value $\approx 0$ \\
\hline
\end{tabular}




\section{CONCLUSION AND FUTURE RESEARCH}

There is no doubt that GFC is one of the important and serious matters that affected the various aspects of life in the world's economic, political and financial areas which was a strong incentive for a number of researchers in different countries to study the effects of GFC in many ways. The current study is one of the first studies in the Middle East area that addresses the impact of GFC on the use of emotional language in annual reports using a sample of banks from six countries. The current study used emotion analysis of banks' annual reports through three periods (pre-GFC, during GFC, and post-GFC) based on eight categories suggested by Plutchik (1980), namely joy, sadness, anger, fear, trust, disgust, surprise, and anticipation. The results of the study showed that the percentage of emotional words in banks' annual reports (from 2002-2017) represents almost 25\% on average. Details for this percentage are as follows:

- the trust category accounts for $36.5 \%-46 \%$;

- the anticipation category is scored for $21 \%-23.9 \%$;

- the fear category accounts for $8.31 \%-15.3 \%$;

- the joy category ranges from $8.53 \%$ to $11.7 \%$;

- the anger category accounts for $4.62 \%-7.75 \%$;

- the sadness category is $4.88 \%-8.59 \%$;

- the surprise category accounts for $1.64 \%-2.91 \%$; and

- the disgust category is $0.81-2.43 \%$.

Moreover, the graphs showed that three categories, namely trust, anticipation and fear, were the most affected over other emotional categories during GFC where the trust category decreased, while both the fear and anticipation categories increased. To test the four hypotheses of the current study, the Wilcoxon test was used. It was found that the trust category has dominated the disgust category in three periods, thus $H 1$ and Pollyanna hypothesis are accepted. Similarly, $H 3$ is accepted where the anticipation category has dominated the surprise category in all periods of the study. Consequently, Pollyanna hypothesis is confirmed. In contrast, $\mathrm{H} 2$ and $\mathrm{H} 4$ were rejected.

The study has some limitations. For example, the study was based on a sample of 12 banks from six countries in the Middle East area. This sample is relatively small. Consequently, the generalization of the study's results may be difficult. This matter can be justified by the difficulty of obtaining annual reports for 16 years for many listed banks in the stock exchanges of the six countries under study. In addition, the study used graphics to show the use of emotional words in each bank through 16 years. Consequently, a limited number of banks is required. The current study opens new horizons to study the relationship between the use of emotional language in financial reports and many key issues such as financial performance, stock prices, corporate governance, risk disclosure and others.

\section{ACKNOWLEDGEMENT}

The authors would like to thank the editor of Banks and Bank Systems journal for valuable comments and co-operation. They also are very grateful for the helpful comments provided by two anonymous referees on the draft that improved the paper a lot. 


\section{REFERENCES}

1. Abraham, S., \& Cox, P. (2007).

Analyzing the determinants of narrative risk information in UK FTSE 100 annual reports. The British Accounting Review, 39(3), 227-248.

2. Al-Najjar, F. S., Noor, M., AlAhmad, N. M., \& Issa, S. S. (2010). The global financial crisis and its impact on the financial sector in Jordan: Applied study on financial companies listed in Amman stock exchange. Journal of International Finance and Economics, 10(1), 1-13. Retrieved from https:// www.researchgate.net/publication/314217315

3. Aly, D., El-Halaby, S., \& Hussainey, K. (2018). Tone disclosure and financial performance: evidence from Egypt. Accounting Research Journal, 31(1), 63-74.

4. Aman, S., \& Szpakowicz, S. (2007). Identifying expressions of emotion in text. Proceedings of the International Conference on Text, Speech and Dialogue (pp. 196-205). Berlin: Springer. https:// doi.org/10.1007/978-3-540-746287_27

5. Arfin, F. N. (1993). Annual reports that pay their way. London: Pitman Publishing.

6. Batson, C. D., Shaw, L. L., \& Oleson, K. C. (1992). Differentiating affect, mood, and emotion: Toward functionally based conceptual distinctions. In M. S. Clark (Ed.), Review of personality and social psychology, No. 13. Emotion (pp. 294-326) Thousand Oaks, CA, US: Sage Publications, Inc.

7. Bellegarda, J. R. (2010). Emotion analysis using latent affective folding and embedding. Proceedings of the NAACL HLT 2010 workshop on computational approaches to analysis and generation of emotion in text (pp. 1-9). Los Angeles, California: Association for Computational Linguistics. Retrieved from https://pdfs.semanticscholar. org/af9a/d6dc0ad6ea46e52d400b522b237f1e6c2f8e.pdf
8. Chan-Lau, J. A. (2010). The Global financial crisis and its impacts on the Chilean banking system (IMF working paper, WP/10/108).

9. Chen, Y. J. (2014). Detecting fraud in narrative annual reports (SSRN scholarly paper No. ID 2511629). Rochester, NY: Social Science Research Network. Retrieved from http://papers.ssrn.com/abstract $=2511629$

10. Conrad, S., \& Biber, D. (2000). Adverbial Marking of Stance in Speech and Writing. In S. Hunston \& G. Thompson (Eds.), Evaluation in Text: Authorial Stance and the Construction of Discourse (pp. 56-73). Oxford: Oxford University Press.

11. Davis, A., Piger, J., \& Sedor, L. (2012). Beyond the numbers: measuring the information content of earnings press release language. Contemporary Accounting Research, 29(3), 845-868. https://doi.org/10.1111/ j.1911-3846.2011.01130.x

12. Easley, D., \& O' Hara, M. (2004). Information and the cost of capital. Journal of Finance, 59(4), 15531583. https://doi.org/10.1111/ j.1540-6261.2004.00672.x

13. Ekman, P. (1992). An argument for basic emotions. Cognition and Emotion, 6(34), 169-200. https://doi. org/10.1080/02699939208411068

14. Ekman, P., \& Cordaro, D. (2011). What is meant by calling emotions basic? Emotion review, 3(4), 364-370. https://doi. org/10.1177/1754073911410740

15. Ekman, P., \& Friesen, W. V. (1971). Constants across cultures in the face and emotion. Journal of Personality and Social Psychology, 17(2), 124-129. http://dx.doi. org/10.1037/h0030377

16. Gibbons, J., \& Chakraborti, S. (2003). Nonparametric Statistical Inference (4th ed.). New York: Marcel Dekker, Inc.

17. Goel, S., Gangolly, J., Faerman, S. R., \& Uzuner, O. (2010). Can linguistic predictors detect fraudulent financial filings? Journal of Emerging Technologies in Accounting, 7(1), 25-46. http://dx.doi.org/10.2308/ jeta.2010.7.1.25

18. Handel, S. (2011). Classification of Emotions. Retrieved from http:// www.theemotionmachine.com/ classification-of-emotions/

19. Henry, E. (2008). Are investors influenced by how earnings press releases are written? Journal of Business Communication, 45(4), 363-407. https://doi. org/10.1177/0021943608319388

20. Hildebrandt, H. W., \& Snyder, R. D. (1981). The Pollyanna Hypothesis in Business Writing Initial Results, Suggestions for Research. International Journal of Business Communication, 18(1), 5-15. https://doi. org/10.1177/002194368101800102

21. Hope, O.-K., Hu, D., \& Lu, H. (2016). The benefits of specific risk-factor disclosures. Review of Accounting Studies, 21(4), 10051045. https://doi.org/10.1007/ s11142-016-9371-1

22. Huang, X., Teoh, S. H., \& Zhang, Y. (2014). Tone management. Accounting Review, 89(3), 10831113. Retrieved from http://ssrn. com/abstract $=1960376$

23. Jaeschke, R., Lopatta, K., \& Yi, C. (2018). Managers' use of language in corrupt firms' financial disclosures: evidence from FCPA violators. Scandinavian Journal of Management, 34(2), 170-192. https://doi.org/10.1016/j.scaman.2018.01.004

24. Jegadeesh, N., \& Wu, D. (2013). Word power: a new approach for content analysis. Journal of Financial Economics, 110(3), 712-729. https://doi.org/10.1016/j. jfineco.2013.08.018

25. Jensen, M., \& Meckling, W. (1976). Theory of Firm: Managerial Behavior, Agency Costs and Ownership Structure. Journal of Financial Economics, 3(4), 305-360.

26. Kohut, G., \& Segars, A. (1992). The president 's letter to 
stockholders: an examination of corporate communication strategy. The Journal of

Business Communication, 29(1), 7-21. https://doi. org/10.1177/002194369202900101

27. Kothari, S. P., Li, X., \& Short, J. E. (2009). The effect of disclosures by management, analysts, and business press on cost of capital, return volatility, and analyst forecasts: a study using content analysis. Accounting Review, 84(5), 1639-1670. https://doi. org/10.2308/accr.2009.84.5.1639

28. Lee, B., Park, J., Kwon, L., Moon, Y., Shin, Y., Kim, G., \& Kim, H. (2018). About relationship between business text patterns and financial performance in corporate data. Journal of Open Innovation: Technology, Market, and Complexity, 4(3), 1-18. https:// doi.org/10.1186/s40852-0180080-9

29. Lee, H., Surdeanu, M., MacCartney, B., \& Jarafsky, D. (2014). On the importance of text analysis for stock price prediction. In Proceedings of the 9th International Conference on Language Resources and Evaluation, LREC 2014 (pp. 1170-1175). European Language Resources Association (ELRA). Retrieved from https://nlp.stanford.edu/pubs/lrec2014-stock.pdf

30. Li, F. (2008). Annual report readability, current earnings, and earnings persistence. Journal of Accounting and Economics, 45(2-3), 221-247. https://doi.org/10.1016/j. jacceco.2008.02.003

31. Li, M. (2018). Emotion analysis from text (Ph.D. Thesis). The Hong Kong Polytechnic University.

32. Loughran, T. \& McDonald, B. (2014). Measuring readability in financial disclosures. Journal of Finance, 69(4), 1643-1671. https:// doi.org/10.1111/jofi.12162

33. Loughran, T., \& McDonald, B. (2011). When is a liability not a liability? Textual analysis, dictionaries, and 10-Ks. Journal of Finance, 66(1), 35-65. https:// doi.org/10.1111/j.15406261.2010.01625.x
34. Mayew, W. J., Sethuraman, M., \& Venkatachalam, M. (2014). MD\&A disclosure and the firm 's ability to continue as a going concern. Accounting Review, 90(4), 1621-1651. Retrieved from http://www.fox.temple.edu/cms/ wp-content/uploads/2012/11/ MSV11012012.pdf

35. Mohammad, S. M. (2018). NRC Emotion Lexicon. http://saifmohammad.com/WebPages/NRCEmotion-Lexicon.htm (Accessed on June 6,2018 ).

36. Nazir, M. S., Safdar, R., \& Akram, M. I. (2012). Impact of global financial crisis on banks' financial performance in Pakistan. American Journal of Scientific Research, 78, 101-110. Retrieved from https://ssrn.com/ abstract $=2615286$

37. Nelson, K. K., \& Pritchard, A. C. (2016). Carrot or stick? The shift from voluntary to mandatory disclosure of risk factors. Journal of Empirical Legal Studies, 13(2), 266-297. https://doi.org/10.1111/ jels. 12115

38. Norris, F. (2007). A new kind of bank run tests old safeguards. The New York Times. Retrieved from http:// www.nytimes.com/2007/08/10/ business/10liquidity.html (accessed on August 10, 2018).

39. Olaniyi, T. A., \& Olabisi, Y. O. (2011). Causes and Impacts of Global Financial Crisis on the Performance of Nigerian Banks (A case Study of Selected Banks). E3 Journal of Business Management and Economics, 2(4), 164-170. Retrieved from http://www.e3journals.org/cms/ articles/1330776455_Olaniyi\%20 and\%20Olabisi.pdf

40. Ortony, A., Clore, C., \& Collins, A. (1988). The Cognitive Structure of Emotions. New York: Cambridge University Press.

41. Pang, B., \& Lee, L. (2004) A sentimental education: Sentiment analysis using subjectivity summarization based on minimum cuts. In Proceedings of the 42nd annual meeting on Association for Computational Linguistics (Article No. 271). https://doi. org/10.3115/1218955.1218990
42. Pang, B., Lee, L., \& Vaithyanathan, S. (2002). Thumbs up? Sentiment Classification using Machine Learning Techniques. In Proceedings of the ACL-02 Conference on Empirical Methods in Natural, Language Processing (EMNLP), 10, 79-86. https://doi. org/10.3115/1118693.1118704

43. Plutchik, R. (1980). Emotion: A Psych evolutionary Synthesis. New York: Harper \& Row.

44. Rajgopal, S., \& Venkatachalam, M. (2011). Financial reporting quality and idiosyncratic return volatility. Journal of Accounting and Economics, 51(1/2), 1-20. Retrieved from https://ideas.repec. org/a/eee/jaecon/v51y2011i12p1-20.html

45. Rogers, J. L., Buskirk, A. V., \& Zechman, S. L. C. (2011). Disclosure tone and shareholder litigation. Accounting Review, 86(6), 2155-2183.

46. Saif, H., He, Y., \& Alani, H. (2012). Semantic sentiment analysis of twitter. In Proceedings of the 11th International Semantic Web Conference (pp. 508524). Retrieved from https:// link.springer.com/chapter/10.1007/978-3-642-35176-1_32

47. Scheibman, J. (2002). Point of view and grammar: structural patterns of subjectivity in American English conversation (187 p.). Philadelphia: John Benjamins Publishing.

48. Schleicher, T., \& Walker, M. (2010). Bias in the tone of forward-looking narratives. Accounting and Business Research, 40(4), 371-390.

49. Smith, M., \& Taffler, R. (2000). The chairman 's statement - A content analysis of discretionary narrative disclosures. Accounting Auditing and Accountability Journal, 13(5), 624-646. https://doi. org/10.1108/09513570010353738

50. Sprent, P., \& Smeeton, N. C. (2007). Applied Nonparametric Statistical Methods (4th ed.). Chapman and Hall.

51. Subramanian, R., Insley, R., \& Blackwell, R. (1993). Performance and readability: a comparison 
of annual reports of profitable and unprofitable corporations. International Journal of Business Communication, 30(1), 49-61.

52. Tama-Sweet, I. (2014). Changes in earnings announcement tone and insider sales. Advances in Accounting, 30(2), 276-282. https://doi.org/10.1016/j.adiac.2014.09.006

53. Tetlock, P. C., Saar-Tsechansky, M., \& Macskassy, S. (2008). More than
Words: Quantifying Language to Measure Firms' Fundamentals.

The Journal of Finance, 63, 14371467.

54. Thomas, J. (1997). Discourse in the marketplace: the making of meaning in annual reports. The Journal of Business Communication, 34(1), 46-77.

55. United Nations. (2011). World economic situation and prospects
2011. Retrieved from https://unctad.org/en/Docs/wesp2011_en.pdf

56. Wall Street Journal. (2007).

TED Spread spikes in July 2007.

Wall Street Journal. Retrieved from http://www.princeton. edu/ pkrugman/ted-spread-wsj. gif (accessed on January 10, 2018).

57. Watson, A., Shrives, P., \& Marston, C. (2002). Voluntary disclosure of accounting ratios in the UK. The British Accounting Review, 34(4), 289-313.

\section{APPENDIX A}

Table A1. List of banks used in the current study

\begin{tabular}{|c|c|c|}
\hline Country name & Name & Code \\
\hline \multirow{2}{*}{ Kingdom of Bahrain (two banks) } & Ahli United bank & $A \cup B$ \\
\hline & Bahrian-Kuwait bank & BBK \\
\hline \multirow{2}{*}{ United Arab Emirates (two banks) } & Dubai Islamic bank & DIB \\
\hline & MashreqbankPSc & MASQ \\
\hline Sultanate of Oman (one bank) & HSBC Bank Oman & $\mathrm{HBMO}$ \\
\hline \multirow{3}{*}{ Jordan (three banks) } & Capital Bank of Jordan & EXFB \\
\hline & The Housing Bank for Trade and Finance & THBK \\
\hline & Jordan Kuwait Bank & JOKB \\
\hline \multirow{2}{*}{ Kuwait (two banks) } & Burgan Bank & BURG \\
\hline & Gulf Bank & GBK \\
\hline \multirow{2}{*}{ Kingdom of Saudi Arabia (two banks) } & Saudi British Bank & SAAB \\
\hline & National Commercial Bank & NCB \\
\hline Total selected banks & 12 Banks & \\
\hline
\end{tabular}

